\title{
Daytime Thermodynamic and Airflow Structures over Northeast Bangladesh during the Pre-Monsoon Season: A Case Study on 25 April 2010
}

\author{
Fumie MURATA \\ Faculty of Science, Kochi University, Kochi, Japan \\ Toru TERAO \\ Faculty of Education, Kagawa University, Takamatsu, Japan \\ Masashi KIGUCHI \\ Institute of Industrial Science, University of Tokyo, Tokyo, Japan
}

Azusa FUKUSHIMA

Graduate School of Urban Environmental Sciences, Tokyo Metropolitan University, Hachioji, Japan

Koji TAKAHASHI

Graduate School of Integrated Arts and Sciences, Kochi University, Kochi, Japan

Taiichi HAYASHI

Disaster Prevention Research Institute, Kyoto University, Uji, Japan

\author{
Arjumand HABIB, Md. Shameem Hassan BHUIYAN, and Sayeed Ahmed CHOUDHURY \\ Bangladesh Meteorological Department, Dhaka, Bangladesh
}

(Manuscript received 30 May 2010, in final form 16 October 2010)

\begin{abstract}
Simultaneous intensive radiosonde observation at three stations over northeast (Sylhet), central (Dhaka), and northwest (Bogra) Bangladesh was analyzed to describe a three-dimensional thermodynamic and airflow structures on 25 April 2010, in which a distinct nocturnal rainfall occurred at Sylhet. As the observation was conducted in the daytime, the observed structures represent convectively inactive condition in a diurnal cycle. Local circulation was unclear and larger-scale airflow was dominated over Sylhet. The radiosonde observation indicated strong subsidence within 1-5 km over Dhaka and Bogra and within 4-5 km over Sylhet, whereas topographic uplifting of southwesterly airflow was observed within 1-3 km over Sylhet. Temperature profiles of Sylhet up to $3 \mathrm{~km}$ were lower than that of other stations, and easterly wind was observed at the surface.
\end{abstract}

Corresponding author: Fumie Murata, Faculty of

Science, Kochi University, 2-5-1, Akebonocho, Kochi

780-8520, Japan.

E-mail: fumie@kochi-u.ac.jp

(C) 2011, Meteorological Society of Japan 


\section{Introduction}

Precipitation systems over the Indian monsoon region are important, because they interact with the monsoon circulation through release of latent heat, and they impact on the economy and human society over the Indian monsoon region through occurrence of natural disasters. One of the most prominent features of the precipitation systems in this region is the diurnal cycle. Studies for the diurnal variability of precipitation systems over this region have been made mainly by satellites, such as geostationary meteorological satellites (e.g., Murakami 1983; Ohsawa et al. 2001; Islam et al. 2004) and Tropical Rainfall Measuring Mission (e.g., Krishnamurti and Kishtawal 2000; Bhatt and Nakamura 2005). However, most of the studies for diurnal precipitating systems over the Indian monsoon region have been concentrated on the monsoon season, and the studies focusing on the premonsoon season are rare.

High-resolution data is needed for not only convective properties, but also other dynamic and thermodynamic variables to understand the mechanism of diurnal time-scale precipitation systems. However, it is difficult to obtain the observational data which would be enough to resolve the diurnal time-scale and to reveal the effect of the complicated topography. The intensive observation has provided valuable observational facts to understand the mechanism, but these studies are still limited (e.g., Barros and Lang 2003; Ueno et al. 2008).

Northeast Bangladesh is located in the windward side of the Meghalaya Plateau (Fig. 1), and it is known as one of the heaviest rainfall areas (Murata et al. 2007). Topographic lifting by the Meghalaya Plateau is considered one of the important factors for the heavy precipitation (Murata et al. 2008). The rainfall variability has a prominent nocturnal peak (Ohsawa et al. 2001), and Kataoka and Satomura (2005) simulated the nocturnal rainfall in this area. While most of the studies for the rainfall variability are concentrated on the monsoon season, the heavy rainfall in this area begins in the premonsoon season (Kripalani et al. 1996; Pant and Kumar 1997). Recently Terao et al. (2008, 2009) showed that the nocturnal rainfall in this area was also dominant in the pre-monsoon season.

The pre-monsoon precipitation systems in Bangladesh are characterized by severe local storms, locally known as "nor'wester" or "Kalbaishaki", which bring gusty wind, severe thunder, hail and

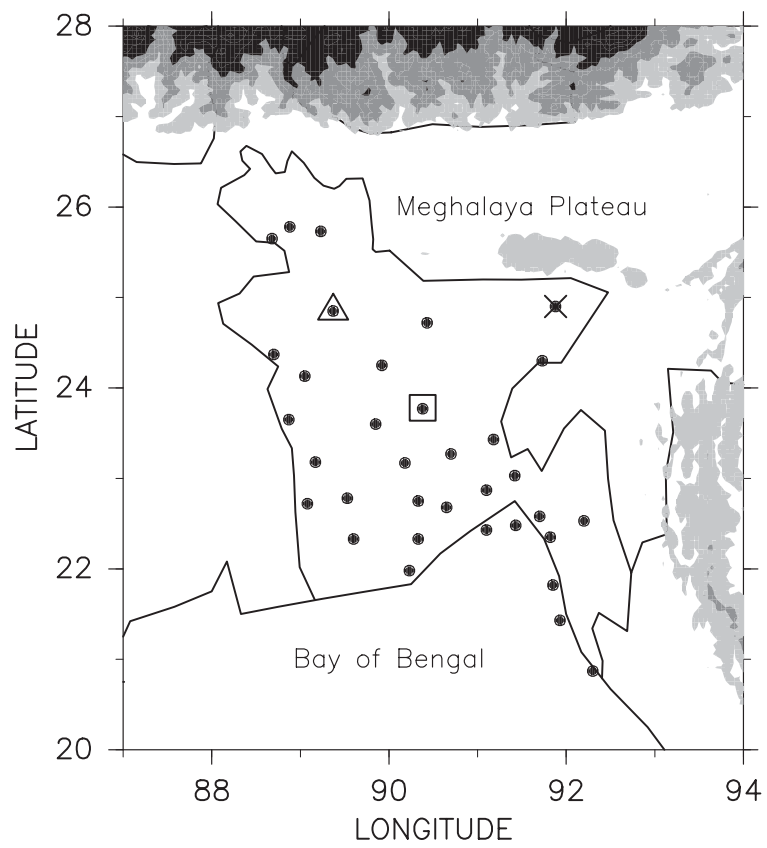

Fig. 1. Location of observation sites. Thirtyfour observatories of Bangladesh Meteorological Department are indicated. Square, cross, and triangle signs represent Dhaka, Sylhet, and Bogra, respectively. The topography with more than $1,000 \mathrm{~m}$ level is shaded.

tornado (e.g., Karmakar and Alam 2006; Yamane et al. 2010). These severe storms appear over northern India and the southern slope of the Himalayas. Recently, severe thunderstorms-observation \& regional modeling (STORM) program has been conducted by the government of India to develop the understanding of these phenomena and to improve forecast over northern India (Joseph 2005).

Our intensive radiosonde observation was carried out to understand the pre-monsoon convective systems. We installed a new radiosonde station at northeast Bangladesh (Sylhet), and provided additional radiosondes for the intensive observation to radiosonde observatories of Bangladesh Meteorological Department (BMD), at central (Dhaka) and northwest (Bogra) Bangladesh (see Fig. 1). The launch time was decided at 0600, 0900, and 1200 UTC (corresponding 1200, 1500, 1800 Bangladesh standard time), because the severe local storms tend to develop in the afternoon (e.g., Joseph 2005; Yamane et al. 2010). The convections over the main target area of this study (northeast 
Bangladesh) were suppressed during the observation time.

This observation was a first opportunity to observe three-dimensional thermodynamic and airflow structures over Bangladesh. In this paper, we describe a specific day with nocturnal precipitation (25 April 2010), and discuss a possible cause of the daytime suppression of convection over northeast Bangladesh. We utilized Bangladesh Standard Time (BST $=\mathrm{UTC}+6$ hours) to describe results.

\section{Data}

\subsection{Radiosondes}

Radiosonde systems provided by International Met Systems and two types of radiosondes (iMet 1-AA and iMet 1-AB) were used for the observation. The iMet 1-AA radiosondes were provided to the Bangladesh Meteorological Department (BMD) upper-air stations at Dhaka $(90.38 \mathrm{E}, 23.77 \mathrm{~N}, 8 \mathrm{~m}$ ASL) and Bogra (89.37 E, 24.85 N, $18 \mathrm{~m} \mathrm{ASL}$ ) for the intensive observation. The iMet 1-AA radiosondes do not have pressure sensors and height is measured by a geostationary positioning system. BMD has employed the same radiosonde systems for a routine upper-air observation since October 2007. We utilized the routine observations in April 2010 to show general features and temporal variation, and the observation frequency was once per day at 0000 UTC (0600 BST). We installed a new radiosonde system at Sylhet $(91.88 \mathrm{E}, 24.90 \mathrm{~N}$, $34 \mathrm{~m}$ ASL), and conducted the intensive observation with the iMet 1-AB radiosondes. A pressure sensor is equipped with the iMet 1-AB radiosonde. The locations are presented in Fig. 1. Three launches were conducted at 1200, 1500 and 1800 BST on 25 April 2010.

\subsection{Surface meteorological data}

We utilized a tipping-bucket type rain gauge which has been installed at Sylhet BMD observatory (91.88 E, $24.90 \mathrm{~N}, 34 \mathrm{~m}$ ASL). The tipping volume is $0.5 \mathrm{~mm}$, and the tipping time is recorded on the logger. The surface wind and temperature data in April 2010 was obtained from an automatic weather station (Vaisala WXT520 with a data logger provided by Oriental Electronics, Inc.), which has been installed at the Sylhet airport BMD office $(91.87 \mathrm{E}, 24.96 \mathrm{~N})$. The recording time is every one minute, and the hourly average is utilized in this paper. The three-hourly surface wind data in 2002-2008 for 34 stations (Fig. 1) over Bangladesh were provided by BMD.

\subsection{Other data}

The daily mean NCEP/NCAR reanalysis data (Kalnay et al. 1996) with a horizontal resolution of 2.5 degrees in longitude and latitude were utilized for understanding a larger-scale distribution of geopotential height and horizontal wind. The black body temperature observed by Multi-functional Transport Satellite (MTSAT-1R) which was provided by Kochi University was utilized for understanding a larger-scale convective activity. Hourly data were used with horizontal resolution of 0.5 degree in longitude and latitude.

\section{Results}

\subsection{Surface and upper-air condition in April 2010}

Figure 2 clearly indicates nocturnal rainfall and daytime convective suppression at Sylhet during the pre-monsoon season. It represents diurnal rainfall variation during 1 March through 26 April 2010 at Sylhet BMD station. Daily rainfall is represented by 24 hours rainfall from 1200 BST because it is convenient to express one night's rainfall. Heavy rainfall commenced from the end of March, and concentrated during 1800 BST through 0900

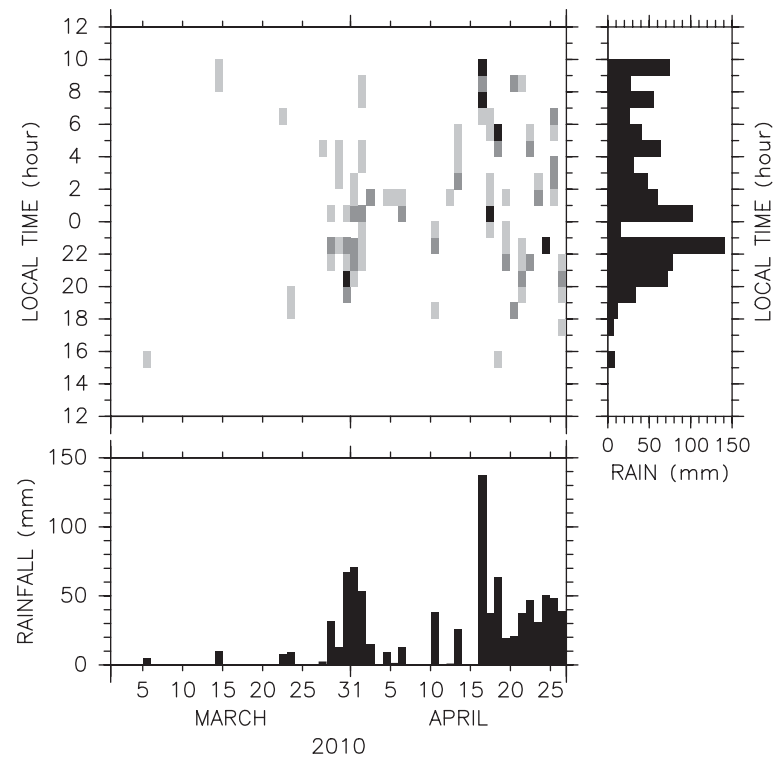

Fig. 2. Hourly rainfall at Sylhet BMD station during 1 March through 26 April 2010. Shade levels show hours with hourly rainfall exceeding $30 \mathrm{~mm} \mathrm{~h}^{-1}$ (dense), $10 \mathrm{~mm} \mathrm{~h}^{-1} \quad$ (medium), and $1 \mathrm{~mm} \mathrm{~h}^{-1}$ (light). Daily rainfall is represented by 24 hours rainfall from 1200 BST. 
(a) ZONAL WIND

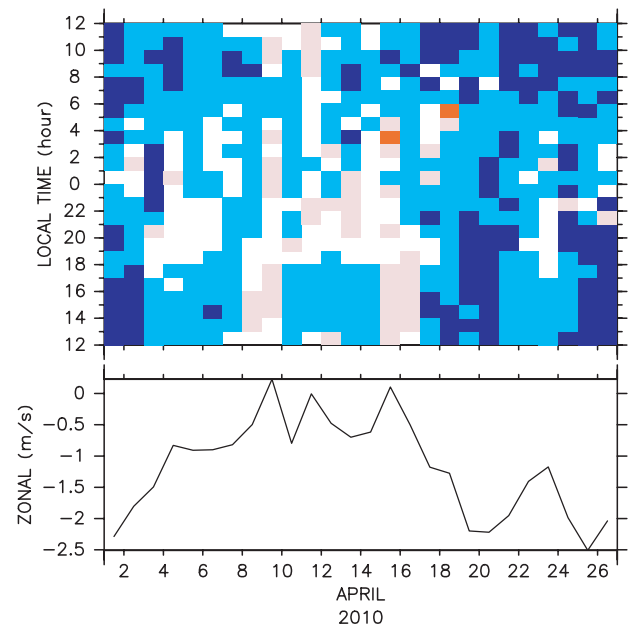

(b) MERIDIONAL WIND

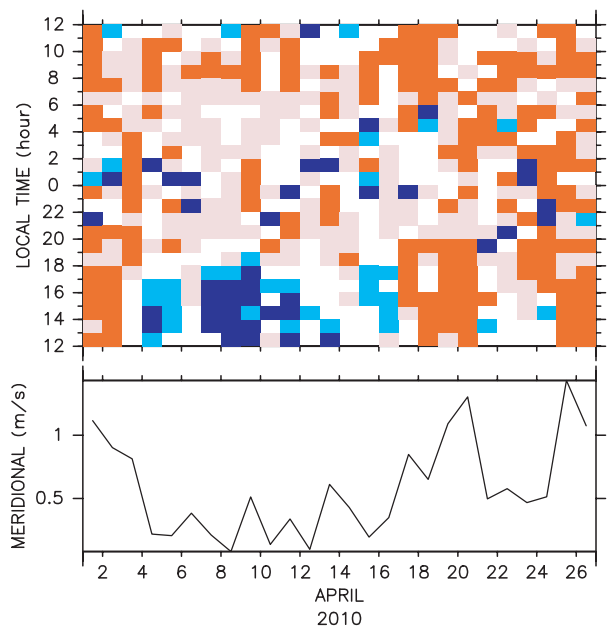

(c) TEMPERATURE

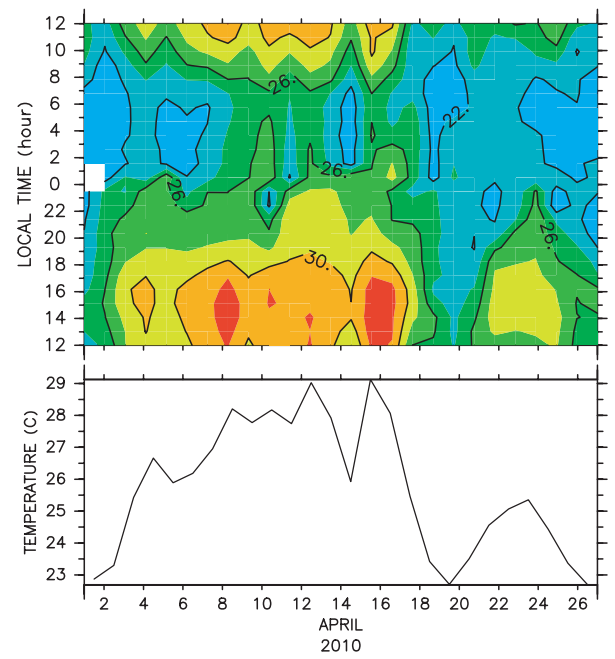

Fig. 3. Hourly surface (a) zonal and (b) meridional wind components, and (c) temperature at Sylhet Airport during 1-26 April 2010. Red (blue) colors in wind components show hours when more than $0.5 \mathrm{~m} \mathrm{~s}^{-1}$ westerly (easterly) wind and southerly (northerly) wind were observed. Dense shade levels represent data of more than $2.0 \mathrm{~m} \mathrm{~s}^{-1}$ for zonal wind and $1.0 \mathrm{~m} \mathrm{~s}^{-1}$ for meridional wind. Contours in (c) are isotherms of 22,26 , and $30^{\circ} \mathrm{C}$. Daily averages are represented by 24 hours average from $1200 \mathrm{BST}$.

BST of the next morning, whereas little rainfall was observed during 1000 BST through 1700 BST. Daily rainfall had an intraseasonal variation, and active phases occurred during 28 March through 2 April and 16-26 April.

Figure 3 shows surface wind components and temperature at Sylhet Airport during 1-26 April 2010. Red (blue) colors in Figs. 3a, b show hours of more than $0.5 \mathrm{~m} \mathrm{~s}^{-1}$ westerly (easterly) wind and southerly (northerly) wind. Dense shade levels represent more than $2.0 \mathrm{~m} \mathrm{~s}^{-1}$ for zonal wind, and
$1.0 \mathrm{~m} \mathrm{~s}^{-1}$ for meridional wind. As the station is located at around $30 \mathrm{~km}$ just south of the Meghalaya Plateau, diurnal local circulation with southerly wind (northerly wind) in the daytime (night time) has been expected, however it was not evident. Instead, southeasterly wind was dominant over the period and the easterly wind component was more dominant than the southerly wind component. The southeasterly wind strengthened in the daytime (1000-1800 BST) of 1-2 April and 17-26 April, and it corresponded with the heavy rainfall days 
(a) ZONAL WIND

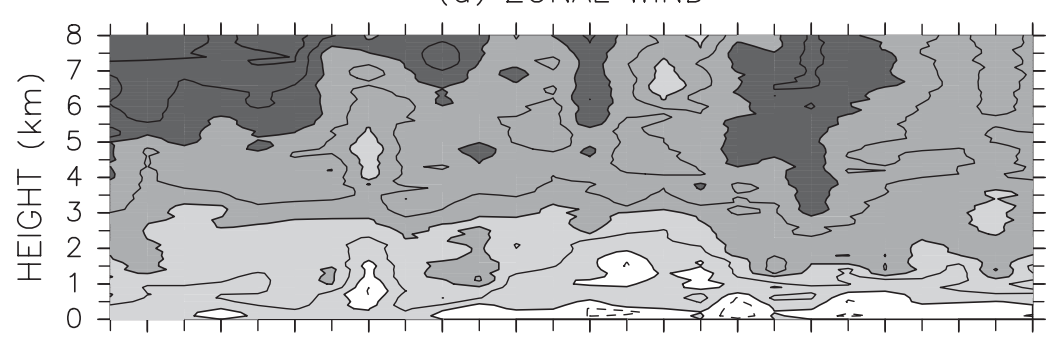

(b) MERIDIONAL WIND

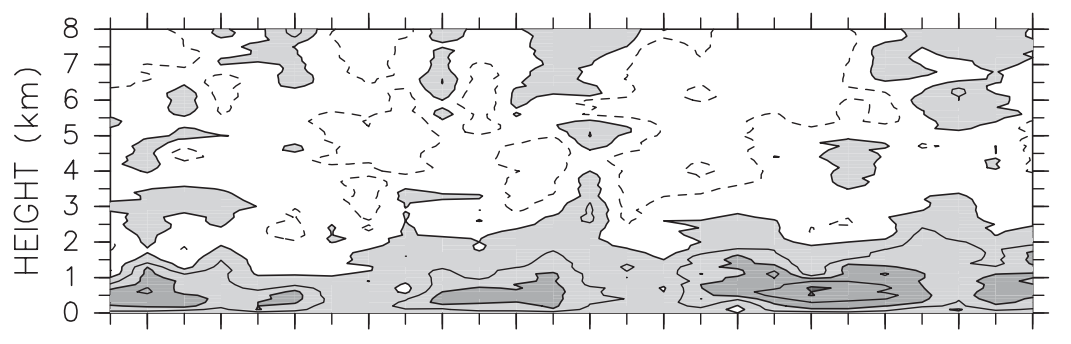

(c) THETAE \& GRADIENT THETA

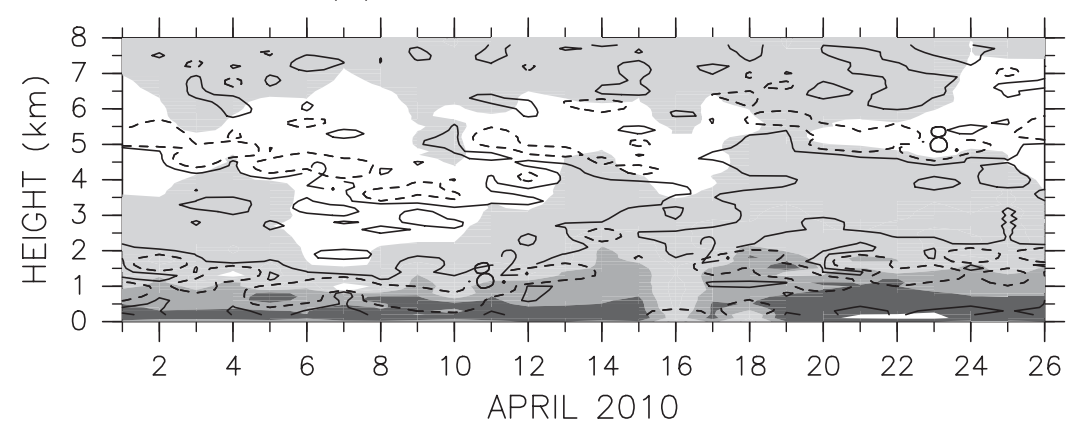

$(\mathrm{m} / \mathrm{s})$

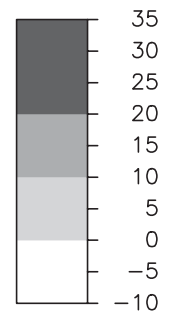

$(\mathrm{m} / \mathrm{s})$

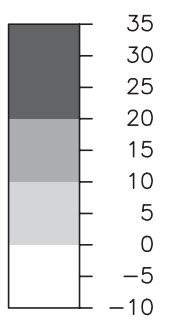

$(\mathrm{K})$

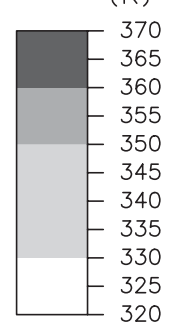

Fig. 4. Time series of (a) zonal wind, (b) meridional wind, and (c) thermodynamic variables up to $8 \mathrm{~km}$ observed at Dhaka during 1-26 April 2010. Contours in (a) and (b) are $5 \mathrm{~m} \mathrm{~s}^{-1}$ intervals. Shades in (c) represent equivalent potential temperature. Solid and dashed contours in (c) represent gradient of potential temperature with $2 \mathrm{~K} \mathrm{~km}^{-1}$ and $8 \mathrm{~K} \mathrm{~km}^{-1}$, respectively.

(Fig. 2). Figure 3c shows a distinct diurnal cycle in temperature during 3-16 April, and it corresponded with periods of little rainfall (Fig. 2). It should be noted that temperature was low throughout the whole day during the heavy rainfall days (1-2 April and 17-26 April) even though nocturnal rainfall was dominant.

Figure 4 shows timeseries of upper-air atmospheric conditions during 1-26 April 2010 obtained from the routine radiosonde observations launched at 0000 UTC (0600 BST) at Dhaka. Southerly wind was dominant below $1 \mathrm{~km}$ (Fig. $4 \mathrm{a})$ and westerly wind became stronger with height (Fig. 4b) throughout the period. High equivalent potential temperature $\left(\theta_{e}\right)$ with more than $350 \mathrm{~K}$ was con- fined below $1 \mathrm{~km}$, and the minimum $\theta_{e}$ was located at around $5 \mathrm{~km}$ (Fig. 4c). Stable layers with large positive gradient of potential temperature $\left(d \theta / d z \geq 8 \mathrm{~K} \mathrm{~km}^{-1}\right)$ was constantly appear at around $1-2 \mathrm{~km}$ and $4-6 \mathrm{~km}$, whereas neutral layer $\left(0 \leq d \theta / d z \leq 2 \mathrm{~K} \mathrm{~km}^{-1}\right)$ was situated within $1-5 \mathrm{~km}$. The strong westerly wind component expanded toward downward within $1-3 \mathrm{~km}$ during 1-2 April and 18-26 April, and it corresponded with the heavy rainfall days at Sylhet (Fig. 2).

\subsection{Synoptic condition on 25 April}

Figure 5 shows $925 \mathrm{hPa}$ geopotential height and wind distribution by NCEP/NCAR reanalysis on 25 April 2010. A developed thermal low was 


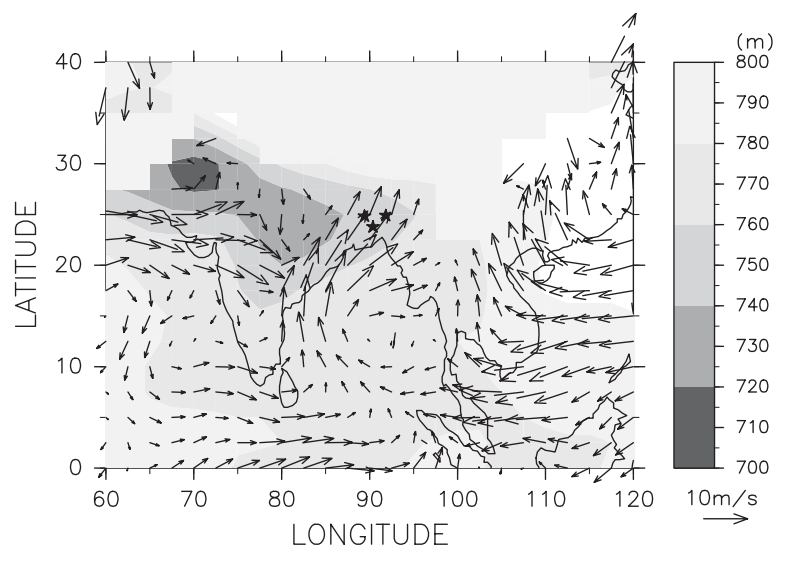

Fig. 5. Geopotential height (shades) and wind (vectors) of NCEP/NCAR reanalysis on 25 Apr 2010 at $925 \mathrm{hPa}$. Three stars are the locations of radiosonde observations. Elevation above 1,000 m was omitted.

situated in the northern Indian subcontinent with northwest through southeast direction. Bangladesh was located on the eastern edge of the thermal low and it was covered by strong southwesterly airflow from the western Bay of Bengal.

Figure 6 represents MTSAT black body temperature $\left(T_{B B}\right)$ over Bangladesh on 25 April 2010. A developing convective system was located in the middle of Bangladesh at 0600 BST and it moved toward the southeast. Bangladesh was gradually covered by high $T_{B B}$ from the west in the daytime. Another convective system appeared over east of the Meghalaya Plateau since 0900 BST. Smaller convection was located on the Plateau in the daytime, whereas large, deep convections developed and covered northeast Bangladesh since 2100 BST, and moved toward the southeast.

\subsection{Results of intensive radiosonde observation}

Figure $7 \mathrm{a}$ shows thermodynamic profiles at Sylhet for temperature, potential temperature $(\theta)$, equivalent potential temperature $\left(\theta_{e}\right)$, and saturated equivalent potential temperature $\left(\theta_{e s}\right)$ at 1200 UTC (i.e., 1800 BST) on 25 April 2010. The convective activity over Meghalaya Plateau was intensified during 1800-2100 BST (see Fig. 1). An Interesting feature was found that a highest $\theta_{e}$ layer with $351 \mathrm{~K}$ was located at $1.2 \mathrm{~km}$. The layer was already saturated and it had high convective available potential energy $\left(4516 \mathrm{~J} \mathrm{~kg}^{-1}\right)$ with $\mathrm{LNB}$ (Level of Neutral Buoyancy) of $11.5 \mathrm{~km}$. The air above $3 \mathrm{~km}$ was dry and a stable layer was located at $2.5-3 \mathrm{~km}$. The hodograph up to $8 \mathrm{~km}$ (Fig. $7 \mathrm{~b}$ ) showed strong vertical shear below $3 \mathrm{~km}$. Easterly wind was dominant at the lowest level (less than $500 \mathrm{~m}$ ) and it changed southwesterly wind between $1-2 \mathrm{~km}$. The northwesterly wind was dominant above $3 \mathrm{~km}$.

Figure 8 shows comparison of thermodynamic profiles between Sylhet, Dhaka and Bogra on 0600, 0900, and 1200 UTC (i.e., 1200, 1500, and 1800 BST) on 25 April 2010. Temperature profiles at Sylhet show several degrees lower than the other two stations below $3 \mathrm{~km}$. A well-mixed boundary layer appeared in the $\theta$ and $\theta_{e}$ profiles of Dhaka and Bogra below $1 \mathrm{~km}$, up to an inversion layer, whereas the profile in Sylhet show more stable profile below $1 \mathrm{~km}$. An inversion layer at Sylhet existed at around $3 \mathrm{~km}$. Dry layer covered above the inversion layers, and the $\theta$ and $\theta_{e}$ profiles showed almost the same values between $1-5 \mathrm{~km}$ at Dhaka and Bogra, and between $3-5 \mathrm{~km}$ at Sylhet. These profile shapes imply the evidence of subsidence, and are discussed in Section 4.2.

Figure 9 shows zonal wind (Figs. 9a, c) and meridional wind (Figs. 9b, d) components at 1200 BST (Figs. 9a, b) and 1800 BST (Figs. 9c, d). The profiles at Sylhet (black lines) are compared with Dhaka (red lines) and Bogra (blue lines). The 10$20 \mathrm{~m} \mathrm{~s}^{-1}$ westerly wind was presented above $2 \mathrm{~km}$ at all three stations. The meridional wind profiles below $3 \mathrm{~km}$ of Sylhet were different from that of the other two stations. The southerly wind with $10 \mathrm{~m} \mathrm{~s}^{-1}$ was presented below $1 \mathrm{~km}$ and it was covered by a weak northerly wind at $1-2 \mathrm{~km}$ at Dhaka and Bogra, whereas the southerly wind layer was dominant below $3 \mathrm{~km}$ at Sylhet, and the southerly wind was the maximum at $1 \mathrm{~km}$. The southerly wind layer with $10 \mathrm{~m} \mathrm{~s}^{-1}$ wind speed became thick at 1800 BST compared with 1200 BST.

Fig. 6. (a)-(h) 3-hourly MTSAT black body temperature (0000, 0300, 0600, 0900, 1200, 1500, 1800, 2100 UTC) on 25 April 2010 (i.e., 0600, 0900, 1200, 1500, 1800, 2100 BST on 25 April and 0000, 0300 BST on 26 April). Three stars are the locations of radiosonde observations. Areas with more than $290 \mathrm{~K}$ is no shading. 
(a) 06 BST

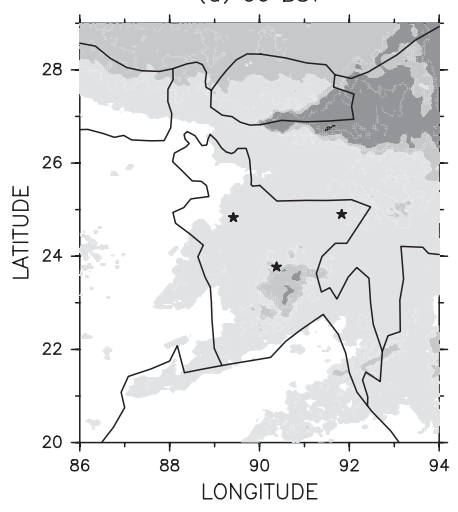

(c) 12 BST

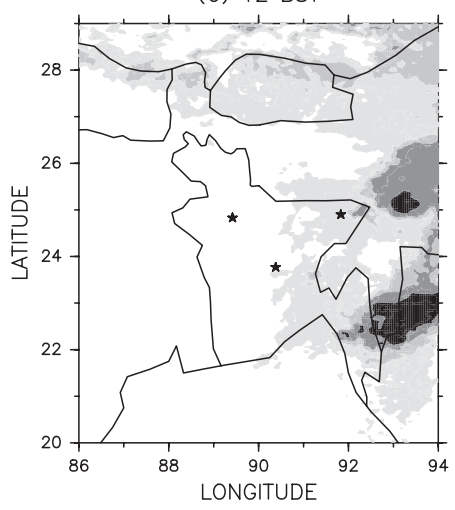

(e) 18 BST

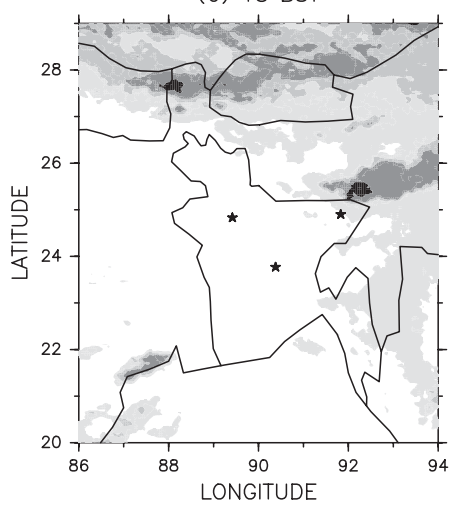

(g) 00 BST

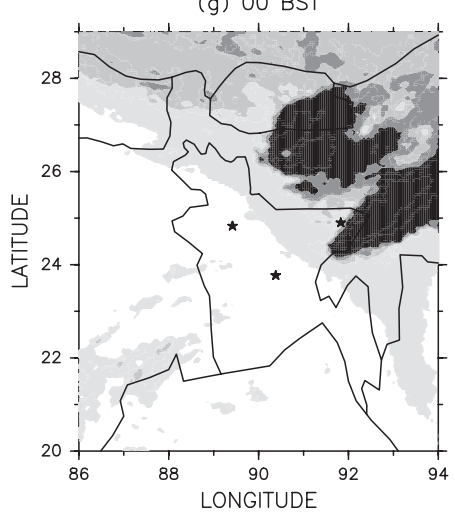

(b) 09 BST

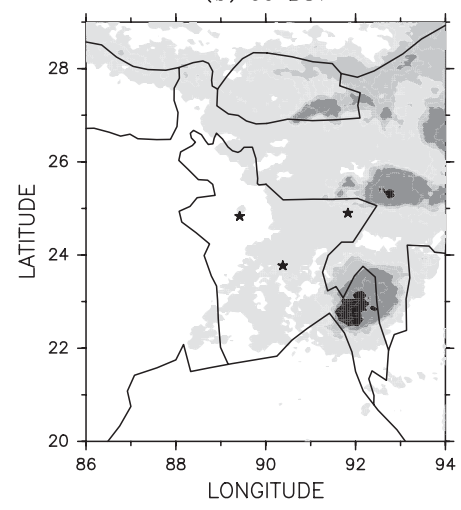

(d) $15 \mathrm{BST}$

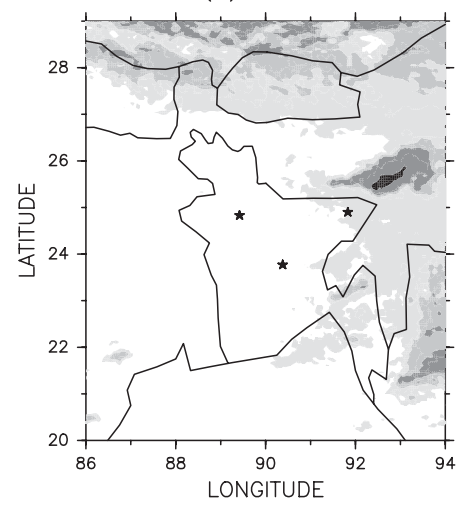

(f) 21 BST

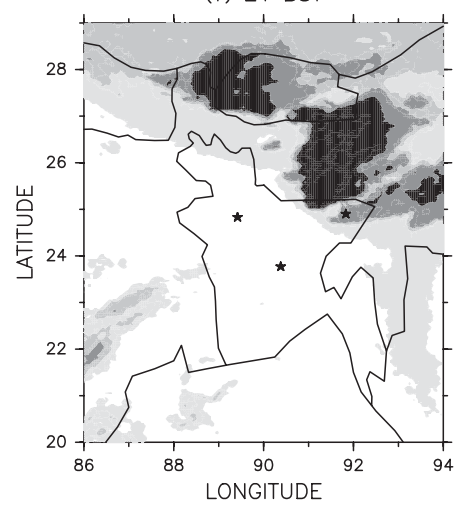

(h) 03 BST

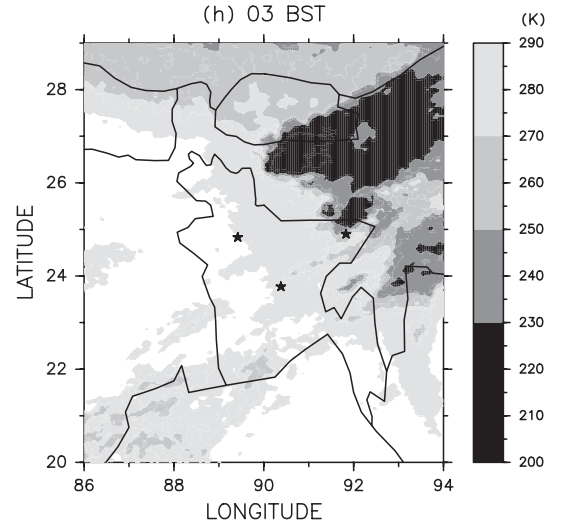


(a)

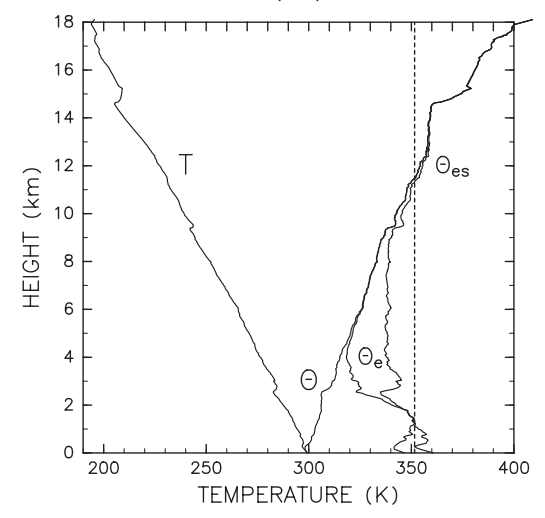

(b)

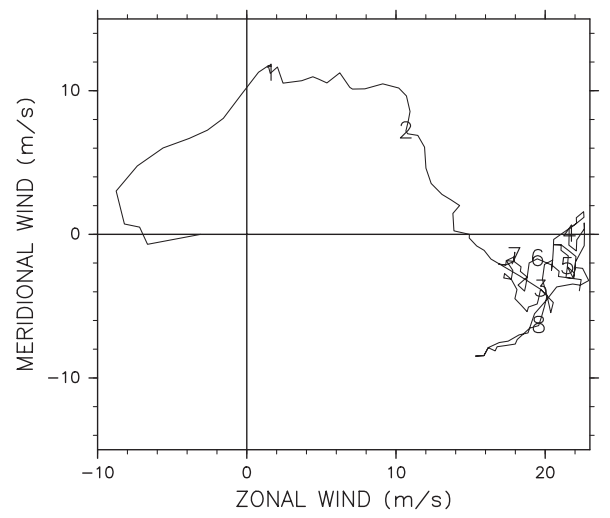

Fig. 7. (a) Thermodynamic profiles for $T, \theta, \theta_{e}$, and $\theta_{e s}$ and (b) hodograph at Sylhet on 1200 UTC (i.e., 1800 BST) 25 April 2010. The dotted line in (a) represents the highest $\theta_{e}(351 \mathrm{~K})$.

(a) 12 BST

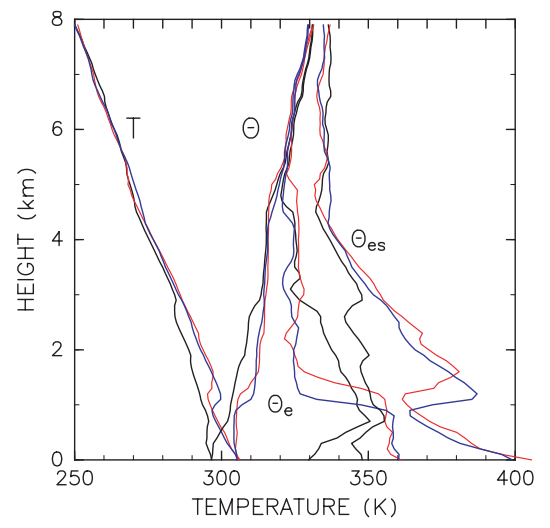

(b) 15 BST

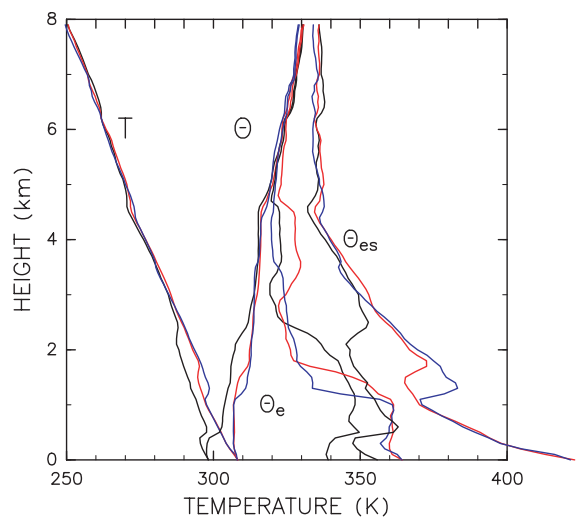

(c) $18 \mathrm{BST}$

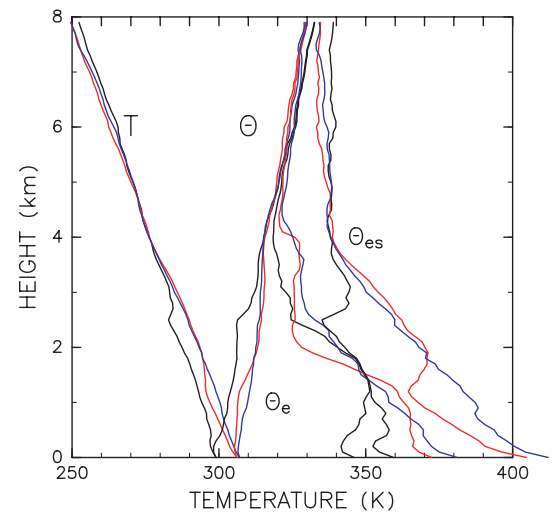

Fig. 8. Thermodynamic profiles of $T, \theta, \theta_{e}$ and $\theta_{e s}$ on (a) 0600 UTC (i.e., 1200 BST), (b) 0900 UTC (i.e., 1500 BST), and (c) 1200 UTC (i.e., 1800 BST) 25 April 2010. The black, red, and blue solid lines represent profiles at Sylhet, Dhaka and Bogra, respectively. 
(a) 12 BST, U

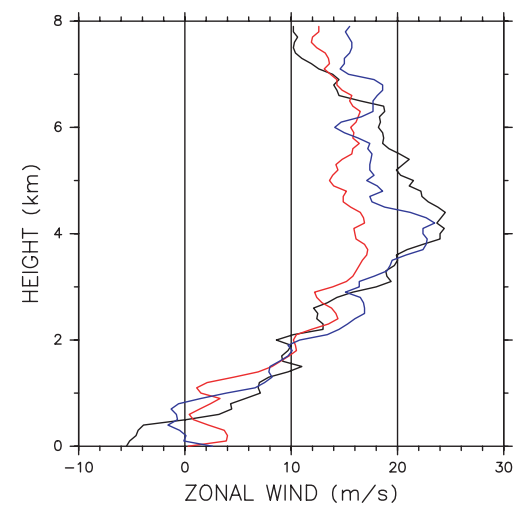

(c) 18 BST, U

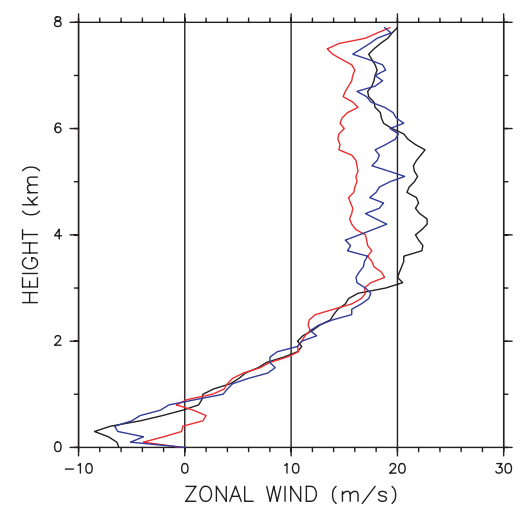

(b) 12 BST, V

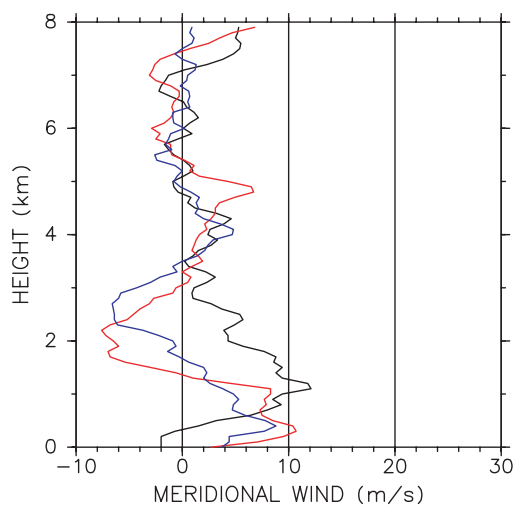

(d) 18 BST, V

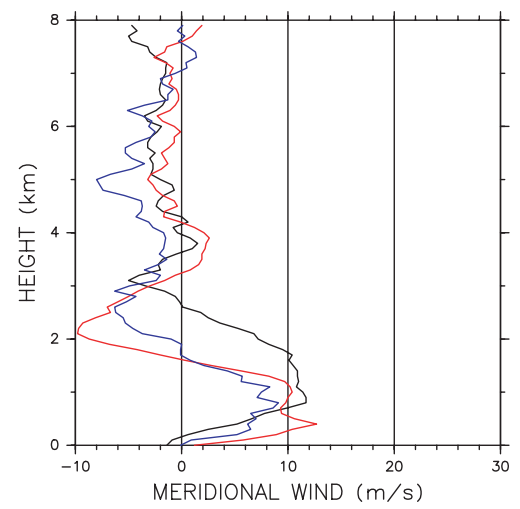

Fig. 9. Profiles of (a), (c) zonal and (b), (d) meridional winds at Sylhet on (a), (b) 0600 UTC (i.e., 1200 BST) and (c), (d) 1200 UTC (i.e., 1800 BST) 25 April 2010. The black, red, and blue solid lines represent profiles at Sylhet, Dhaka and Bogra, respectively.

\section{Discussion}

\subsection{Uplift of southerly wind layer}

Strong southwesterly wind was blowing at $925 \mathrm{hPa}$ over Bangladesh on 25 April 2010 (Fig. $5)$. The southerly wind layer was confined below $1 \mathrm{~km}$ at Dhaka and Bogra, whereas the southerly wind layer existed within 1-3 km at Sylhet (Fig. 9). As the southwesterly wind blew from the low land of the Bengal Plain to the Meghalaya Plateau with the highest level of 1,965 $\mathrm{m} \mathrm{ASL}$, the uplift of the layer due to topographical effect is expected. The strong southwesterly wind with more than $10 \mathrm{~m} \mathrm{~s}^{-1}$ within 1-2 $\mathrm{km}$ corresponded with heavy rainfall days at Sylhet in April 2010 (Figs. 2, 4), and it implies the importance of strong uplifting airflow for heavy rainfall over northeast Bangladesh.

\subsection{Subsidence}

The $\theta$ and $\theta_{e}$ profiles at Dhaka and Bogra within $0-1 \mathrm{~km}$ and $1-5 \mathrm{~km}$ on 1200 BST showed almost isothermal and there was a distinct stable layer between the layers within $0-1 \mathrm{~km}$ and $1-5 \mathrm{~km}$ (Fig. $8)$. This means that both layers within $0-1 \mathrm{~km}$ and $1-5 \mathrm{~km}$ were filled with air with the almost same potential temperature and absolute humidity, and it implies the layer is well mixed or under a largescale vertical advection. Similar structure was also evident on 1500 and 1800 BST though the stable layer at $1 \mathrm{~km}$ was raised with time. Routine radiosondes observed at 0600 BST at Dhaka (Fig. 4c) showed that the neutral layer within $1-5 \mathrm{~km}$ and the stable layer at around $1 \mathrm{~km}$ were common features throughout April 2010. The uniform layer within $0-1 \mathrm{~km}$ is regarded as the result of daytime boundary layer mixing. There is a large difference 
of both $\theta_{e}$ and $\theta_{e s}$ values between the upper and the lower layers of the stable layer at $1 \mathrm{~km}$, and it implies the abrupt decrease of absolute humidity in the upper layer. The profiles of $\theta_{e}$ and $\theta_{e s}$ in the upper part of the stable layer show like 'an onion shape' described by Zipser (1977). These features imply that the uniform layer within $1-5 \mathrm{~km}$ is considered as the result of large-scale adiabatic subsidence. The similar uniform layer appears in the profiles of 4-5 km at Sylhet. The temperature layer below $3 \mathrm{~km}$ at Sylhet has several degrees lower values than that of Dhaka and Bogra. The 1-3 km layer corresponded with the topographic uplift region of southwesterly wind at Sylhet, whereas it corresponded with the subsidence region at Dhaka and Bogra. Therefore, the temperature difference within 1-3 km between Sylhet and the other two stations must be determined by whether adiabatic heating by the subsidence existed or not.

Webster (1987) drew a subsidence from equatorial convective region in the schematic figure of meridional circulation along $90^{\circ} \mathrm{E}$, and the subsidence was located within $5-12 \mathrm{~km}$. Sato and Kimura (2006) discussed the dynamical and thermal effects of the Tibetan Plateau on the midtropospheric subsidence $(400 \mathrm{hPa})$ over northern India by using a simplified regional climate model. However, these subsidences from tall equatorial convections or by the effects of the Tibetan Plateau with the elevation of more than $4000 \mathrm{~m}$ must be located too high level to explain the strong subsidence observed within 1-5 km. Minoura et al. (2003) utilized the European Centre for MediumRange Weather Forecasts reanalysis data, and showed the shallow vertical circulation up to $500 \mathrm{hPa}$ between ascending motion over the inland of the Indian subcontinent and subsidence over the adjacent ocean. They discussed that the shallow circulation was formed by a thermally induced low below $850 \mathrm{hPa}$ over the Indian subcontinent and a thermal high at $600-700 \mathrm{hPa}$ in the relation of thermal wind balance (Xie and Saiki 1999). As our study area is in the periphery of the thermal low (Fig. 5), a plausible cause of the observed subsidence is the descending branch of the shallow circulation between thermal low region and the adjacent region.

\subsection{Cold pool}

The near surface temperature below $1 \mathrm{~km}$ at Sylhet was several degrees lower than that of Dhaka and Bogra (Fig. 8). While the $\theta$ and $\theta_{e}$ profiles at
Dhaka and Bogra at 1200 BST showed the development of the boundary layer below $1-1.5 \mathrm{~km}$ up to the inversion layer, the profiles at Sylhet were stable below $1 \mathrm{~km}$. Surface temperature variation in April 2010 (Fig. 3c) showed the prominent low temperature throughout the heavy rainfall days. It is suggested that this is the effect of a remnant cold pool produced by the nocturnal precipitation.

The near surface wind at Sylhet was easterly (Figs. 7b, 9). It is considered as the result of the zonal pressure gradient between the high pressure due to the existence of a cold pool over northeast Bangladesh and the thermal low in the western part (Fig. 5). The surface zonal wind in April 2010 (Fig. 3) showed that the easterly wind was intensified during the active convective periods over Sylhet (Fig. 2), and the fact supports this hypothesis.

Kataoka and Satomura (2005) simulated the nocturnal precipitation over northeast Bangladesh by a non-hydrostatic cloud-resolving model, and revealed that a deep cold pool was formed over the surface by precipitation. The cold pool can lift the warm southerly airflow up to the level of free convection at the southern boundary of the cold pool, then it had an important role for the development of subsequent convective systems. Though their simulation was conducted for the monsoon period, the similar easterly wind was produced as a result of the cold pool in their simulation (Fig. 5 in their paper).

The dominance of easterly wind was observed throughout April 2010 (Fig. 3). Figure 10 shows the dominant surface wind distribution over Bangladesh in April during 2002 through 2008. The southerly wind is dominant in the south of $24^{\circ} \mathrm{N}$, whereas the easterly wind is dominant in the north of $24^{\circ} \mathrm{N}$. This implies the strong pressure gradient between the thermal low over the west and the cold air mass by the frequent precipitation over the east produce climatological surface wind distribution.

\subsection{Possible cause of nocturnal rainfall}

The airflow structures derived from the observational results in the daytime on 25 April 2010 were summarized in schematic figures (Fig. 11). The westerly wind became strong with height under the existence of the subtropical jet stream that blew the south of the Tibetan Plateau in the premonsoon season. Under strong subsidence within 1-5 km, moist southwesterly airflow with high $\theta_{e}$ that was confined below $1 \mathrm{~km}$ at Dhaka and Bogra 


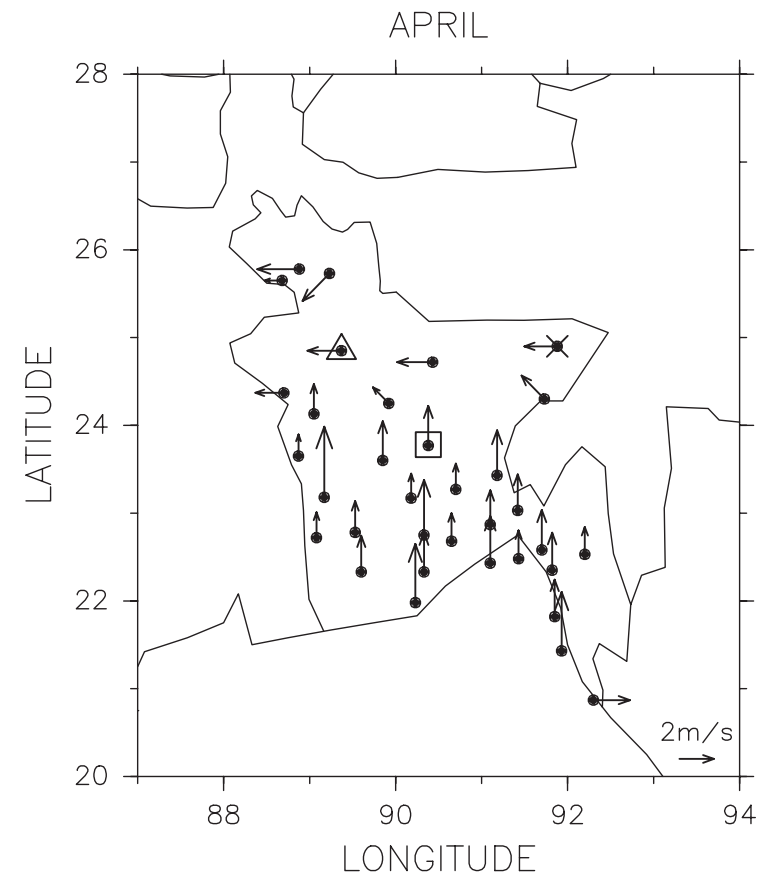

Fig. 10. Dominant surface wind directions and its average wind speed at 34 stations of Bangladesh Meteorological Department in April during 2002 through 2008. Square, cross, and triangle signs represent Dhaka, Sylhet, and Bogra, respectively.

were uplifted up to $3 \mathrm{~km}$ by the Meghalaya Plateau. A stable layer was formed at the boundary of the moist air and the dry upper air. Another stable layer was drawn around $5 \mathrm{~km}$ according to Figs. $4 c, 8$. Temperature over Sylhet region was lower than that of Dhaka and Bogra below $3 \mathrm{~km}$ because of the remnant cold pool over Sylhet region below $1 \mathrm{~km}$ and the adiabatic heating over Dhaka and Bogra within 1-3 km. At near the surface, easterly wind blew between thermal low in the west of Dhaka and Bogra and the cold air mass over Sylhet region.

The dominance of southerly wind below $1 \mathrm{~km}$, intensified westerly wind with height, the subsidence within $1-5 \mathrm{~km}$, and the stable layers at around 1 and $5 \mathrm{~km}$ were common features in April 2010 (Fig. 4). The strong moist southwesterly airflow, the cold air mass at the surface over Sylhet, and the intensified easterly wind over the northern Bangladesh characterize heavy rainfall days over Sylhet region (Figs. 3, 4a). The uplift of southwesterly airflow over the Meghalaya Plateau were
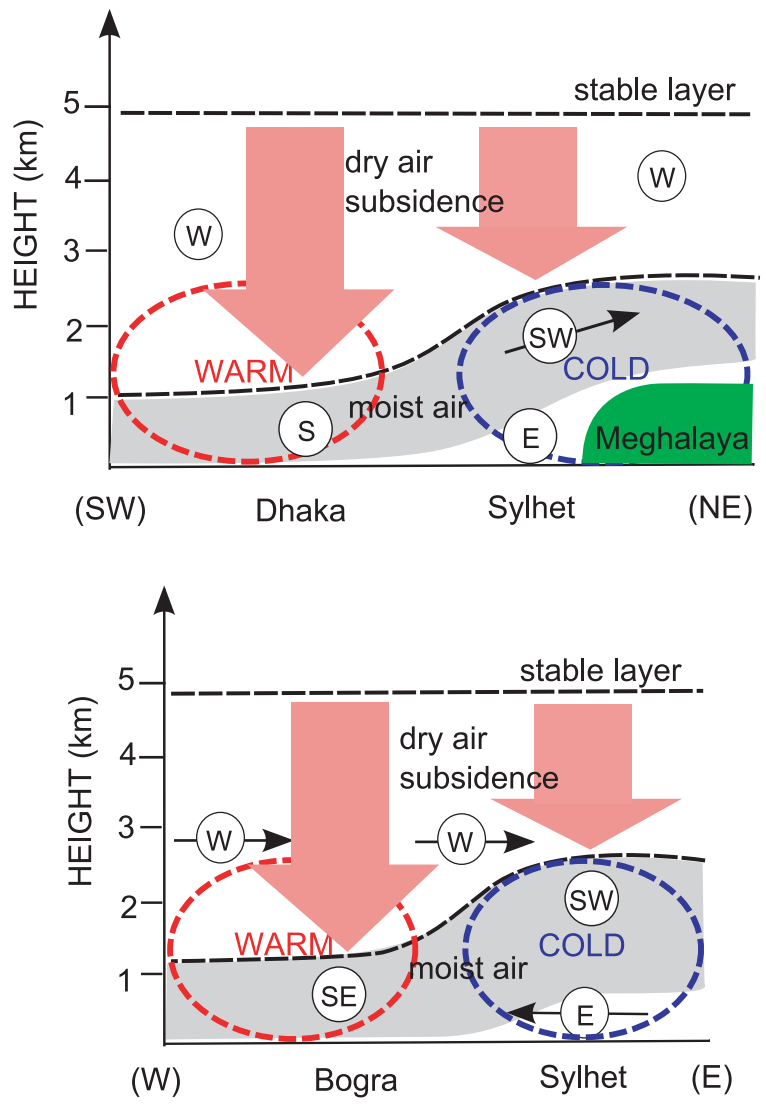

Fig. 11. Schematic figures of observed airflow over northeast Bangladesh in the daytime on 25 April 2010. Upper and lower figures show southwest-northeast cross-section through Dhaka and Sylhet, and west-east cross-section through Bogra and Sylhet, respectively. Red large arrows represent subsidence, and gray regions represent moist airflow with southerly wind component. Wind directions are enclosed by circles, and black arrows are added for the airflow parallel to the cross-sections. Dashed black lines represent stable layers, whereas dashed red and blue circles represent the horizontal temperature gradients.

evident in the other simultaneous radiosonde observations conducted during the heavy rainfall days at Sylhet (22 and 26 April 2010, not shown).

Although the uplift of southwesterly airflow by the Meghalaya Plateau must be the main forcing for heavy precipitation over Sylhet, the uplifting airflow was observed even in the daytime when the convections were inactive. As the southwesterly layer at Sylhet was relatively drier at 1200 and 
1500 BST compared with 1800 BST (Fig. 8), the development of the boundary layer in the upstream of southwesterly airflow may cause the drying of the layer through daytime temperature increase and/or mixing with dry upper air, and it may contribute to the daytime convective suppression over Sylhet. In addition, the remnant cold air mass formed by the nocturnal precipitation can stabilize the daytime atmosphere.

\section{Conclusions}

A simultaneous intensive radiosonde observation at the three stations (Sylhet, Dhaka, and Bogra) over Bangladesh was analyzed for a specific day (25 April 2010) to describe the thermodynamic and airflow structures during the period of nocturnal precipitation over northeast Bangladesh. It was a first opportunity to obtain the three-dimensional thermodynamic and airflow structures over Bangladesh. The nocturnal precipitation was dominant over northeast Bangladesh in April 2010 during the pre-monsoon season, though such a diurnal cycle of precipitation was investigated mainly during the monsoon season. Easterly wind was dominant in the near surface at Sylhet and the local circulation was not apparent in April 2010. The observational facts on 25 April 2010 were as follows. A distinct subsidence was observed within 1-5 km above the well-mixed boundary layer at Dhaka and Bogra, and within 4-5 km at Sylhet, whereas the geographical uplifting of southwesterly airflow was observed within 1-3 km over Sylhet. The atmosphere below $3 \mathrm{~km}$ over Sylhet was covered by cold air compared with the other two stations in the daytime, and the development of a boundary layer was not obvious.

This study revealed a daytime thermodynamic and airflow structure when the nocturnal rainfall occurred over northeast Bangladesh. Though we need further research to examine the obtained facts by comparing with other observations because of the limited analysis, it must be valuable in terms of the understanding of nocturnal rainfall under the complicated geographical effects over the Indian monsoon region.

\section{Acknowledgements}

The intensive radiosonde observation was conducted under the support of Mr. Abdul Awal, Mr. Belal, and other BMD staffs at Dhaka, Bogra, and Sylhet observatories. We are thankful to $\mathrm{Mr}$. Quamrul Alam for his kind assistance with our re- search project. Dr. Someshwar Das at South Asian Association for Regional Cooperation (SAARC) Meteorological Research Center (SMRC) and STORM project team in SMRC kindly provided the useful information about convective activity over the Indian region during the intensive observation. This study was financially supported by a Grant-in-Air for Scientific Research (21403005) of the Japanese Ministry of Education, Science, and Culture, supervised by Dr. Toru Terao. The figures in this paper were produced by GFD-DENNOU Library.

\section{References}

Barros, A. P., and T. J. Lang, 2003: Monitoring the monsoon in the Himalayas: observations in central Nepal, June 2001. Mon. Wea. Rev., 131, 1408-1427.

Bhatt, B. C., and K. Nakamura, 2005: Characteristics of monsoon rainfall around the Himalayas revealed by TRMM precipitation radar. Mon. Wea. Rev., 133, 149-165.

Islam, M. N., T. Hayashi, H. Uyeda, T. Terao, and K. Kikuchi, 2004: Diurnal variations of cloud activity in Bangladesh and north of the Bay of Bengal in 2000. Remote Sensing of Environment, 90, 378388.

Joseph, P. V., 2005: Severe Thunderstorms-Observations \& Regional Modeling (STORM) Programme Science Plan. Department of Science \& Technology, Government of India, $50 \mathrm{pp}$.

Kalnay, E., and Coauthors, 1996: The NCEP-NCAR 40year reanalysis project. Bull. Amer. Meteor. Soc., 78, 437-471.

Karmakar, S., and M. M. Alam, 2006: Instability of the troposphere associated with thunderstorms/ nor'westers over Bangladesh during the premonsoon season. Mausam, 57, 629-638.

Kataoka, A., and T. Satomura, 2005: Numerical simulation on the diurnal variation of precipitation over northeastern Bangladesh: a case study of an active period 14-21 June 1995. SOLA, 1, 205-208.

Kripalani, R. H., S. Inamdar, and N. A. Sontakke, 1996: Rainfall variability over Bangladesh and Nepal: comparison and connections with features over India. Int. J. Climatol., 16, 689-703.

Krishnamurti, T. N., and C. M. Kishtawal, 2000: A pronunced continental-scale diurnal mode of the Asian summer monsoon. Mon. Wea. Rev., 128, 462-473.

Minoura, D., R. Kawamura, and T. Matsuura, 2003: A mechanism of the onset of the South Asian summer monsoon. J. Meteor. Soc. Japan, 81, 563-580.

Murakami, M., 1983: Analysis of the deep convective activity over the western Pacific and Southeast Asia. J. Meteor. Soc. Japan, 61, 60-76. 
Murata, F., T. Hayashi, J. Matsumoto, and H. Asada, 2007: Rainfall on the Meghalaya Plateau in northeastern India-one of the rainiest places in the world. Nat. Hazards, 42, 391-399.

Murata, F., T. Terao, T. Hayashi, H. Asada, and J. Matsumoto, 2008: Relationship between atmospheric conditions at Dhaka, Bangladesh, and rainfall at Cherrapunjee, India. Nat. Hazards, 44, 399-410.

Ohsawa, T., H. Ueda, T. Hayashi, A. Watanabe, and J. Matsumoto, 2001: Diurnal variations of convective activity and rainfall in tropical Asia. J. Meteor. Soc. Japan, 79, 333-352.

Pant, G. B., and K. R. Kumar, 1997: Climates of South Asia. John Willey \& Sons, 320 pp.

Sato, T., and F. Kimura, 2007: How does the Tibetan Plateau affect the transition of Indian monsoon rainfall? Mon. Wea. Rev., 135, 2006-2015.

Terao, T., M. N. Islam, F. Murata, and T. Hayashi, 2008: High temporal and spatial resolution observations of meso-scale features of pre- and mature summer monsoon cloud systems over Bangladesh. Nat. Hazards, 44, 341-351.

Terao, T., M. N. Islam, F. Murata, Y. Yamane, and T. Hayashi, 2009: Diurnal variation of rainfall inten- sity in pre-monsoon and monsoon over Bangladesh and the Northeastern India. In Proceedings of the 2nd International Conference on Water and Flood Management, Institute of Water and Flood Management, Bangladesh University of Engineering and Technology, 317-325.

Ueno, K., K. Toyotsu, L. Bertolani, and G. Tartari, 2008: Stepwise onset of monsoon weather observed in the Nepal Himalaya. Mon. Wea. Rev., 136, 2507-2522.

Webster, P. J., 1987: The elementary monsoon. Fein, J. S. and P. L. Stephens (eds.), Monsoons, Wiley \& Sons, Inc., 3-32.

Xie, S.-P., and N. Saiki, 1999: Abrupt onset and slow seasonal evolution of summer monsoon in an idealized GCM simulation. J. Meteor. Soc. Japan, 77, 949-968.

Yamane, Y., T. Hayashi, A. M. Dewan, and F. Akter, 2010: Severe local convective storms in Bangladesh: Part I. Climatology. Atmos. Res., 95, 400406.

Zipser, E. J., 1977: Mesoscale and convective-scale downdrafts as distinct composents of squall-line structure. Mon. Wea. Rev., 105, 1568-1589. 